\title{
Evolución de los modelos metodológicos y su relación con la política educativa en España
}

Sonsoles San Román Gago'

\begin{abstract}
Resumen
Con base en investigación realizada sobre los marcos institucionales del proceso de cambio social de transición democrática en España y los contextos motivacionales de la participación de las maestras en el actual proceso educativo, este artículo tiene por objetivo esbozar, desde la perspectiva de la sociología, un recorrido histórico del sistema educativo en España desde el comienzo de la escuela pública para comprender la evolución de los modelos culturales, ideológicos, metodológicos y curriculares y su relación con los cambios en las política educativa. Está centrado en señalar que, más allá de las cuestiones económicas que implican recortes en educación, se esconde un modelo ideológico interesado o no por dotar a la población de un mayor o menor nivel cultural. La intención es destapar la relación entre cultura, educación y metodología empleada en función de las demandas políticas y comprender el tipo de normas ideadas para producir valores y obtener conductas acordes con los intereses políticos en cada uno de los contextos históricos que se suceden en la evolución de la escuela pública en España. Fue posible percibir que en España no ha habido ni un solo momento en la historia de la escuela pública en el cual los políticos, y en muchas ocasiones la propia Iglesia, no hayan sido los encargados de diseñar los contenidos, currículos y metodologías que dan forma a las políticas educativas.
\end{abstract}

\section{Palabras clave}

Política educativa - Metodología - Cultura - Burocratización Sociología histórica. 


\title{
Evolution of methodological models and its relation with educational policy in Spain
}

Sonsoles San Román Gago'

\begin{abstract}
Based on an investigation about the institutional aspects of the process of social change associated with the democratic transition in Spain, and of the motivational contexts of the participation of teachers in the current educational process, the present article seeks to outline, from the point of view of sociology, the historical path of the educational system in Spain since the beginnings of public school, in order to understand the evolution of the cultural, ideological, methodological and curriculum models, as well as its relation to the changes in educational policies. The work focuses on pointing out that, behind economic issues that imply cuts in education, lies hidden an ideological model interested or not in endowing the population with a higher or lower cultural level. Our intention here is to unveil the relation between culture, education and methodology employed as a function of the political demands, and to understand the kind of norms put in place to produce values and to obtain conducts adequate to the political interests in each one of the historical contexts that have succeeded each other in the evolution of public school in Spain. It was possible to discern that in Spain there has never been a single moment in the history of public school in which the politicians, and in many occasions the Church itself, were not in charge of designing the contents, curricula and methodology that gave shape to the educational policies.
\end{abstract}

\section{Keywords}

Educational policy - Methodology - Culture - Bureaucratization Historical sociology.

I- Universidad Autónoma de Madrid, Madrid,

Spain.Contat: s.sanroman@uam.es 


\section{Una percepción de la educación en el momento actual}

El momento que vive la educación pública en España no puede ser más desolador. Recortes de 10.000 millones de euros en educación van a producir masificación en las aulas al reducir grupos de discentes, parte del profesorado contratado se quedará sin trabajo, algunas de las familias no podrán pagar el coste de las matrículas, que se incrementa considerablemente, al encontrarse en paro. El precio de los másters se incrementa en un 50 por ciento, la ayuda a investigación se reduce vertiginosamente; $y$, curiosamente, las exigencias de calidad y puesta en marcha de nuevas metodologías aumentan.

Por si fuera poco este panorama, cayendo en el absurdo de lo imposible, las exigencias internacionales (Bolonia y Pisa) solicitan de la educación pública la reducción del número de alumnos por grupo para incrementar la calidad y poder implantar metodologías óptimas para aplicar en grupos con menor alumnado. Un sinsentido, una vuelta de tuerca hacia una política neoliberal sin precedentes desde el advenimiento de la democracia. No es mi intención aventurarme en los sinsabores que están por llegar, pero sí destapar esa relación entre cultura, educación y metodología empleada en función de las demandas políticas.

Desde la perspectiva sociológica, manejaremos el término cultura como recreación y disponibilidad para adquirir valores, significaciones, prácticas, para comprender los primeros conceptos básicos de la historia; como la forma de crear y recrear conceptos, de dominar más la relación con el mundo, la relación del hombre consigo mismo. Nos decantamos así por la definición del concepto de cultura que maneja Norbert Elias (1979): "cultura como desarrollo y proceso civilizatorio, como cultura histórica y autorrealización" (p. 49). El término cultura es aplicable de modo más propio al conjunto de conocimientos, que no a la cultura material encarnada en las técnicas y los objetos que una civilización usa, y que es una acepción más propia de la arqueología o de la etnología. En esa perspectiva, entendemos que educación y cultura son dos términos que pueden ser utilizados con el mismo sentido, pues se trata de una acumulación de conocimientos, capacidades y habilidades que se adquieren por varios modos (HARGREAVES, 1994).

Aún sabiendo que la educación y la cultura no se adquieren sólo en la escuela, este artículo se centra en ese terreno para ligar los cambios culturales a los modelos de política educativa y los consiguientes cambios metodológicos: Lancaster, Montesino, etc. Y ello, al entender que más allá de los contenidos, las normas que llegan a través de los currículos dan forma a un tipo de valores sobre el que se asientan las futuras conductas que el poder político espera del modelo de ciudadano. De ahí la importancia de comprender los cambios históricos poniéndoles en relación con las políticas educativas y las preferencias metodológicas en distintas etapas históricas.

Inmersos en un contexto de cambio social y educativo, ante las nuevas necesidades que exige el proceso de apertura y globalización que vive nuestro país, la brecha de apertura internacional que se ha abierto ha modificado, y lo seguirá haciendo, los objetivos y funciones asignados a la escuela - como el Informe Pisa - y a la universidad - como el Proyecto Bolonia (CARABAÑA, 2009; GIMENO SACRISTÁN et al., 2004; VIÑAO FRAG0, 2002, 2004). En esa tormenta ideológica el interés por mejorar la educación se ha centrado no sólo en los contenidos, sino también en la metodología, algo que, por otra parte, no es nuevo en España. Desde los inicios de nuestro sistema educativo, que abordaré más adelante, los momentos de conflicto y cambio social y político se han visto acompasados por nuevos modelos metodológicos. Así fue durante el siglo XIX, la misma tónica continuó en el XX y en la misma dirección parecen apuntar los dirigentes políticos en el XXI (SAN ROMÁN, 2011). 
Las formas de enseñar, recogidas tanto en el Informe Pisa como en el Proyecto Bolonia, se apuntan como soluciones mágicas para crear un ambiente que motive a los estudiantes $\mathrm{y}$ despierte su interés por la cultura. Las soluciones van tanto por la vía de las competencias - los conocimientos que se adquieran deben seguir un currículo lógico para ayudar a solucionar y entender los problemas cotidianos, como del aprendizaje significativo - el profesorado es elegido para motivar y lanzar las flechas de la cultura con la puntería de un experto que da en la diana de la conducta, logrando que el alumno interiorice e interrelacione contenidos de distintas asignaturas (GIMENO SACRISTÁN et al., 2004).

En mi opinión, el problema que se plantea es cómo acometer la mejora de nuestra educación. Por un lado, la Organisation for Economic Co-operation and Development (OCDE) parece apuntar hacia la inversión económica para alcanzar niveles de calidad; por otro, algunos expertos, ateniéndose a los resultados del Informe Pisa, consideran que todos los caminos conducen a Roma, ya que países que no invierten grandes cantidades en educación han logrado buenos resultados.

Los rendimientos académicos que muestran nuestros estudiantes avisan que algo no funciona bien en nuestro sistema educativo, hay un 26,5 por cien de tasa de abandono, el doble que la media europea. Cuesta pensar que la infancia y la juventud de nuestro país no tengan dotes para las matemáticas o la lengua, entre otras materias.

El proceso de burocratización de nuestro sistema educativo ha seguido el tic-tac del reloj de los intereses políticos. En el tejido social de nuestras escuelas, el tira y afloja marcado por los desacuerdos y polémicas creados por el poder político ha terminado por crear confusión y desencanto; un sentimiento de desconcierto ante los continuos cambios que afectan al semblante de la escuela con la puesta en marcha de medidas legislativas que, a modo de socavones, dificultan el paso firme de padres, profesores y alumnos en lo que, en principio, debería ser una tarea de interés común. Adela Cortina (2006) publicó en el periódico El País un interesante artículo sobre la necesidad de abordar la cuestión educativa desde la perspectiva de la suma positiva en la que todos los agentes implicados salen ganando (aula, patio y casa, esto es, la escuela, la sociedad y la familia), evitando así continuar con los juegos de suma cero en los que lo que gana la escuela lo pierden los padres, o viceversa.

Las contradicciones entre lo que dice la ley y lo que se puede poner en práctica chocan con el muro de unas costumbres profundamente instaladas en nuestro modelo social y son, sin duda, un elemento importante a tener en cuenta. No se trata únicamente de buscar una solución económica; se trata de problema de mentalidad que exige la rápida adaptación de medidas adecuadas para modificar algunos hábitos creados por el propio funcionamiento de nuestro sistema burocrático.

\section{El sentido de la cultura}

¿Qué sentido se otorga al término “educación”, o lo que viene a ser lo mismo, a la cultura? En la rueda histórica de ese entramado de años en que transcurre la evolución de nuestro sistema educativo, el término ha sufrido oscilaciones y vaivenes acordes con el contexto histórico y social y, muy concreto, en el caso de nuestro país, con intereses detentados por los sistemas políticos. Las cuerdas del guiñol de la educación no se mueven por azar, como tampoco lo hacen las funciones que se exigen de la escuela, ni la regulación de órdenes, decretos y leyes que bombardean el latido cultural del aula hasta producir arritmias importantes en docentes y discentes. ¡Vaya si hay distancia entre lo que fue la escuela en sus comienzos y las funciones que se le otorgan en la actualidad!

Es obvio que el sentido de la educación ha variado. Remontarnos a sus orígenes nos permitirá visualizar los giros que se han producido en esa organización llamada escuela pública. Interpretar el sentido en ese largo 
recorrido, exige conocer los cambios políticos, económicos, sociales, religiosos y educativos que han variado la textura de las redes de control exigidas por el poder como medio para asegurar el modelo de organización burocrática demandado a la escuela y a los profesores. Weber (1985) señaló con gran acierto que no es posible entender el significado sin relacionarlo con una situación histórica. En efecto, el halo que envuelve la cultura y la educación ha ido variando sus destellos en función de las luces y las sombras que ha ido encontrando en ese largo recorrido histórico. Dibujar el paisaje en este juego de color exige comenzar por los oscuros.

Si volvemos la mirada hacia nuestro pasado histórico vemos que las funciones de la escuela han variado; icómo no habrían de hacerlo ante la lluvia de demandas que han caído sobre esta institución! Escuela y sociedad caminan juntan, unas veces con acuerdos, otras, con grandes controversias. Aunque decir esto no es hacer honor a la verdad, pues desacuerdos en materia educativa siempre han existido en España. No vienen de ahora las luchas y conflictos por tomar el timón del sistema educativo. Es más, aún antes del proceso constituyente de 1834, ya había discordias. Así el sentido otorgado al término cultura en el reinado de Carlos III, Fernando VII o Isabel II (tres monarcas que dejaron señales importantes en esa evolución de nuestro sistema educativo durante finales del siglo XVIII y primera mitad del XIX) devuelve la imagen de una historia fragmentada en los cristales rotos de las ideologías.

\section{Érase una vez...}

A finales del siglo XVIII en España comienzan a aparecer centros para acoger a la infancia y evitar así la ociosidad y malas costumbres con que crecían esos niños y niñas que deambulaban por las calles imitando malos hábitos y costumbres y sin posibilidad de aprender un oficio - que no una profesión - para ganarse la vida e incrementar así la productividad en un país cerrado al comercio que consume lo que produce. Como resultado de este interés productivo, la industria textil se reservó a la mujer y el trabajo agrícola al hombre. Esas primeras escuelas se abrieron durante el reinado de Carlos III.

La educación fue campo de batalla en los cambios políticos de los sucesivos reinados, sufriendo un notable retroceso en el reinado de Fernando VII, con mayor o menor poder de la iglesia en función de los intereses ideológicos de la corona; fluctuando el modo de acceso al cuerpo de maestras y maestros, con intentos por mejorar la calidad de la enseñanza desde una perspectiva que apunta hacia la confianza en la cultura como medio de progreso. Ya en 1812 la Constitución de Cádiz encomendó la ejecución de la gestión al Ministerio de Gobernación, de quien dependía la Dirección General de estudios, estableciendo con ello el embrión de lo que más tarde sería el Consejo de Ministros, órgano independiente del poder ejecutivo que pretendía evitar el monopolio ideológico del Estado y garantizar la libertad de enseñanza. Los intentos por modernizar el país y el interés por legislar un currículo escolar vuelven a plantearse en el Trienio Constitucional: 18211823 (DECRETOS DEL REY FERNANDO VII, 1816, 1826; GIBERT, 1815). En el curso de estos vaivenes políticos se detecta el desacuerdo del sector más liberal, enfrentamiento político que llegaría a la arena de nuestro sistema educativo marcando conocimientos exigidos, nivel de profesionalización, formas de acceso al cuerpo de maestros, etc.

Para ser maestro en el siglo XIX era necesario pasar una prueba de doctrina cristiana, mostrar la peripecia en el arte de leer y escribir, saber contar, demostrar buena vida y costumbres y entregar un certificado de limpieza de sangre. La maestra, sin embargo, sólo necesitaba un informe acerca de su vida y costumbres, y ser examinada de doctrina cristiana "por la persona que dispute el ordinario, y Licencia de la justicia, oído el síndico y personero sobre las diligencias previas" (MARTÍNEZ ALCUBILLA, 1880, p. 1517-1518). 
En los primeros intentos por acercar la cultura a una población necesitada, el exiguo número de maestras y maestros, unido a la falta de una organización escolar centralizada, determinó la metodología a seguir. El método de enseñanza mutua-lancasteriana (HOPMANN, 1991), que permitía al maestro valerse de niños ayudantes para enseñar, resultaba un instrumento de suma eficacia, y muy económico para afrontar la falta de profesorado. De esta manera, sirviéndose de la ayuda de los alumnos, la corona minimizaba los gastos en educación y podía hacer frente a un modelo educativo que estaba dirigido a las clases más desfavorecidas (SAN ROMÁN, 2011).

Las necesidades de escolarización y el sentido otorgado a la cultura vuelven a variar en el contexto del proceso constituyente de 1834 . España tiene que subirse al tren del desarrollo industrial. En la línea de salida tiene una importante desventaja con respecto al resto de los países europeos. Los viajeros que ocuparan los nuevos vagones de la historia no cumplen con las condiciones mínimas para ocupar trabajos que exigen mano de obra cualificada. Ante esta situación, el estado debe acometer la tarea de alfabetizar a la población. El nuevo giro produce una necesidad económica y social que lleva al poder a centrar sus objetivos en la educación de la infancia, pieza clave en ese proyecto político de futuro (MELCÓN BELTRÁN, 1992). El estado debe responder a la nueva necesidad económica y social para hacer frente a la situación social que se le presenta y hacer viable la demanda de escolarización en el ámbito nacional. Para ello, es imprescindible asegurarle una formación académica mínima al profesorado y ampliar sus competencias. Este interés se dirige, en principio, solo hacia los varones.

El concepto de cultura adquiere un nuevo sentido. Se trata de homogeneizar a la infancia en los valores, conductas y hábitos acordes con el nuevo ideario político, como medio de asegurar el orden social. Todo ello da lugar a un cambio de metodología. El método lancasteriano se sustituye por el de Pablo Montesino (1840). Se trata de la mejor solución para hacer realidad las demandas de escolarización y minimizar así los gastos en educación. Para poder abrir escuelas de niños se buscan otras medidas: los maestros ya no son ayudados por sus discípulos, sino por sus esposas, madres o criadas. La estructura familiar se reproduce en la escuela de la mano de un método que considera la disciplina y autoridad del maestro como el mejor medio para garantizar la enseñanza memorística.

El control de las redes del estado cae con fuerza sobre una escuela que ni tiene el número suficiente de maestros, ni cuenta con edificios escolares para responder a las exigencias de ese Estado. La necesidad de paliar esta carencia de medios lleva al poder político a delegar en los ayuntamientos el pago y edificación de centros para acoger a la población escolar.

El Estado controla y delega las cuestiones de pago en los ayuntamientos. De momento, la sensibilidad social por ampliar la escolarización hacia los niños obliga a los ayuntamientos a abrir escuelas para niños, exigencia que se recoge en El Plan de Instrucción primaria de 4 de agosto de 1836. Dos años más tarde, el Plan del 38 ordena, siguiendo la línea de la Ley del 36, la apertura en Madrid de la primera Escuela Normal Central de Maestros (que se abre ese mismo año), y recomienda a los respectivos municipios que establezcan este tipo de centros. Hasta 1846 los ayuntamientos de provincias no estuvieron obligados por ley a abrir escuelas normales masculinas (SCANLON, 1987).

La exigencia de dotar a la infancia de nuevos modelos culturales no salpica, de momento, a la educación de las niñas. La legislación dictada entre 1836 y 1838 nada mandó, tan sólo se limitó a recomendar que las disposiciones se aplicasen, en la "medida de lo posible”, a las escuelas de niñas. Pero el curso del progreso hacia la modernización incrementará las exigencias culturales en la infancia; papel para el cual la mujer resulta imprescindible por su papel de madre. Por ello, ante la necesidad de crear un modelo de infancia acorde con una situación que exige un modelo cultural más elevado, la escolarización se extenderá pronto a las niñas. 
Años más tarde, los disturbios y luchas revolucionarias que se suceden en 1856 pronostican un cambio de gobierno. Narváez llega al poder y formará un gabinete de corta duración (del 12 de octubre de 1856 al 15 de octubre de 1857), pero con repercusiones inmediatas en el terreno educativo (SANZ DÍAZ, 1980). Un año más tarde, en 1857, los esfuerzos de Claudio Moyano se verían recompensados con la aparición de una ley que lleva su nombre, primera Ley General de Educación en nuestro país (MOYANO SAMANIEGO, 1857).

La necesidad de dotar a la población de un mayor nivel cultural es recogida por un Estado que conoce la fuerza del aparato educativo para alcanzar el nuevo modelo de conducta acorde con el régimen socio-político y poder con ello dar respuesta a las necesidades educativas que emergen en España. El control del Estado se extiende ahora a todos los ramos de la instrucción pública, incluida la etapa de primaria (RUIZ BERRIO, 1970).

El estado comienza a acentuar el control, regula formas de acceso y modelos curriculares tomando medidas para profesionalizar el ejercicio del magisterio. Nos encontramos ante un periodo de inflexión clave en la política educativa que explica el embrión de burocratización de nuestro sistema educativo. La Ley Moyano no solo regula las formas de acceso y los modelos curriculares; supone, además, un giro de 180 grados al tomar medidas que favorecerán el ingreso de las mujeres en el sistema educativo. En efecto, para asegurar niveles de cultura en esos maestros que compatibilizan su profesión con ocupaciones como secretario del ayuntamiento, tendero, etc., el estado decide hacer incompatible el ejercicio de maestro. La medida no era nueva puesto que ya había sido legislada en 1838. La incompatibilidad regulada por Moyano iba a producir en adelante el abandono de un buen número de maestros, que buscarían otros trabajos mejor pagados para asegurarse una existencia digna. La primera Ley General de Educación obliga, con diecinueve años de retraso, a abrir escuelas de niñas. Por ello, se crean necesidades de contratación de maestras y apertura de edificios escolares que, nuevamente, recaen en los ayuntamientos. La coeducación estaba prohibida y los ayuntamientos debían duplicar sus gastos al ofertar escuelas para niños y para niñas; con maestros, en un caso, y maestras en otro. Moyano busca medidas para abaratar el sueldo de las maestras ${ }^{1}$ y abrir escuelas para niñas. Se decreta la apertura de la Escuela Normal de Maestras; primer intento oficial por controlar, aunque sea mínimamente, el trabajo que realizan las mujeres (SAN ROMÁN, 2011).

El Gobierno, que obliga y controla, sigue en la línea de confiar a las autoridades locales la responsabilidad de promover y financiar la instrucción pública. Los ayuntamientos debían sufragar estos gastos y las Comisiones locales y provinciales estaban obligadas a promover y vigilar tales escuelas, sin cobrar un real por su trabajo. Los representantes de la autoridad, que no parecían sentirse halagados por la confianza que el legislador venía a depositar en ellos, siguieron actuando como les vino en gana, y esas escuelas o no llegaron a crearse, o lo hicieron al margen de las órdenes dictadas.

Moyano establece diferentes modelos de escuelas en función del censo y riqueza de los ayuntamientos (completas, incompletas, mixtas y de temporada), asegurando así un sistema educativo ligado a un modelo social estratificado. La nueva cultura escolar se aplica para asegurar conductas pacíficas, incapaces de alzarse contra el poder político en un contexto en el cual España necesita igualarse con el resto de los países colindantes (MOYANO SAMANIEGO, 1857, art. 89) y emprender el camino hacia la modernidad.

El gobierno, que se erige como único responsable para señalar lo que se debe o no enseñar (medida que no le gustó al sector más clerical, que entendía que la Iglesia debía

1 - Estas profesoras, que por Ley recibían una tercera parte menos del sueldo de un maestro (MOYANO SAMANIEGO, 1857, art. 191), iban a resultar muy económicas para unos ayuntamientos que se veían forzados a emplear sus partidas económicas en un asunto que no parecía importarles. 
intervenir no sólo en la inspección moral y de las doctrinas que se impartían en los centros, sino también en la designación de profesores y libros de texto), publica cada tres años los libros de texto correspondientes, que pone en conocimiento de la Autoridad eclesiástica con la conveniente anticipación (art. 93), para cursar las asignaturas de primera y segunda enseñanza, las carreras profesionales y los estudios universitarios hasta el grado de licenciado (se exceptúan en las facultades los estudios posteriores a la licenciatura). Posteriormente, la personalidad en quien delegase la Iglesia tenía la competencia de designar los manuales de religión y moral (art. 92). De esta manera, los profesores, son convertidos en muñecos manejados por intereses ideológicos y sometidos a un rígido control estatal.

La política educativa vuelve a girar cuando ese grupo de intelectuales, tan castigados por Isabel II con el infierno del exilio, pudieron regresar a nuestro país en 1868. Regreso conocido por La Gloriosa del 68 que inaugura un nuevo camino que modifica el sentido del término cultura como medio para alcanzar el cambio social que España necesita en el camino hacia la modernidad. Como resultado, los contenidos y métodos de la escuela pública se reorganizan hacia 1882 para afrontar ese cambio. El método de Montesino, memorístico y autoritario, se sustituye por el de Fröebel, basado en la reflexión y la enseñanza lúdica. Poco sucedió en España después de la Restauración, que en materia educativa traza el puente que nos lleva hasta la II República.

\section{Y llegó el siglo XX}

Cuando el 14 de abril de 1931 se proclama en España la Segunda República, se procede a un cambio sin precedentes en la profesionalización del cuerpo de maestros y maestras que produce otro giro en el concepto de cultura (PÉREZ GALÁN, 1988). Las exigencias por elevar el nivel cultural de las y los españoles favorecen al profesorado. El magisterio atraviesa uno de esos momentos afortunados: los estudios se elevan a la categoría de superiores; el sueldo de los docentes se incrementa significativamente; $y$, para conseguir la igualdad entre los sexos, se implanta la coeducación en las escuelas. La inversión en cultura se considera la mejor herencia que el estado puede dejar a los españoles. ${ }^{2}$

Los nuevos dirigentes políticos eran conscientes del papel de la educación como palanca de cambio social y político. Con el fin de paliar el déficit cultural, sus objetivos se dirigen hacia la escuela. Resultaba imprescindible abrir el número de centros educativos necesarios para escolarizar a la infancia - medida decretada por Moyano en 1857, y que seguía sin cumplirse. Según los datos aportados por Ramón Tamames (1973), al comenzar la República el déficit de escuelas de niños y niñas en edades comprendidas entre los 6 y los 12 años era de 27.000. Mariano Pérez Galán (1988) dibuja la situación escolar en el mapa de España al comenzar la República: “32.680 escuelas estaban funcionando, y era necesario crear 27.151 más para poder escolarizar a la población infantil" (p. 37). La formación del nuevo cuerpo de profesores era una pieza clave para instituir un sistema democrático y proclamar una nueva Constitución, en cuya bandera se dibujaban los principios de igualdad y derechos humanos.

El Plan Profesional de 1931 exigía, por primera vez en la historia de España, estar en posesión del título de bachiller para ingresar, y regulaba la duración de los estudios en cuatro años (el cuarto era sólo de prácticas); tesitura que ponía al cuerpo del magisterio en España en la misma situación que el resto de carreras universitarias. Se trataba de crear un nuevo cuerpo de maestros y maestras preparados para hacer frente al nuevo reto social y político. Con el nuevo plan no sólo se modificaron los contenidos de la educación, sino, y lo que es más importante, la metodología (este vuelve a ser un tema de máxima actualidad, pues el

2- Especial calado pedagógico tuvieron las famosas Misiones Pedagógicas, los decretos de normalización lingüística, o la importante política de construcciones escolares para hacer frente a un problema crónico en España. 
interés por los contenidos, que fue uno de los argumentos más defendidos en décadas pasadas, ha sido lentamente sustituido por una tendencia a dar prioridad a las didácticas en el currículo de estos estudios). Se trataba de fomentar el espíritu crítico; y, para ello, en los cuatro años que duraba la carrera por el Plan Profesional de 1931, se enseñaba metodología, pues se creía que el alumnado, que había ingresado con una amplia cultura de bachillerato, entraba ya con los conocimientos necesarios para enseñar.

Pero la Guerra Civil (1936-39) llega y las bases de la modernización se derrumban. Después del levantamiento militar de 18 de julio de 1936, el Estado comienza a reformar la enseñanza para acabar con el modelo republicano de Escuela Única y establecer una Escuela Nacional acorde con el ideario del nacional sindicalismo: escuela nacional, patriótica y nacionalista que prohíbe la coeducación. El cuerpo de profesores formado por el Plan Profesional, que no había cursado religión, fue depurado, expulsado de la escuela pública. Los nuevos maestros y maestras, que quedaban encargados de la socialización de las generaciones más jóvenes en la obediencia al poder establecido y en los principios ideológicos del franquismo, se convertian en pilar fundamental del régimen:

Las Maestras a quienes se encomienda esta tarea, no son las mismas de antes de 1936: son diferentes [...], la conmoción nacional que hemos padecido desde 1936 a 1939 [...], nos ha enseñado lo que es capaz el hombre, cuando, alejado de Dios, reniega de su Patria y de su familia y se entrega a la satisfacción de los apetitos insaciables que exige la fiera que cada hombre lleva dentro. Someter esa fiera al gobierno del espíritu es urgente, y el medio más eficaz es la creación, en cada uno de nosotros, de los valores morales necesarios para dominarlos y gobernarlos. (REVISTA CONSIGNA, 1941, n. 10, p. 10)

La situación es caótica. El magisterio se degrada y hasta 1945 no se convocan oposiciones. ¿Quién cubre las vacantes? Un personal sin preparación ni título que dirigiría el rumbo de la educación pública de nuestro país en ausencia de ese profesorado expulsado de la escuela pública (los maestros y maestras del Plan Profesional de la Segunda República). Pero el tiempo, el más sabio de todos los jueces, terminaría por dar la razón al sentido común solo después de agotar las decrecidas fuerzas del cuerpo de profesores formados paseando por los despachos ministeriales en busca del reconocimiento de sus derechos como profesionales de la educación.

Elnivelcultural decrecesignificativamente. De hecho, los cuatro planes de estudio que se suceden en tan solo 11 años (1940, 1942, 1945 y 1950) muestran tanto las prisas por encontrar un mecanismo capaz de erradicar de una vez por todas los ideales sociales y reformistas de los republicanos, como el intento desmedido por reproducir a través de la escuela un modelo patriótico, religioso y nacional que sirva de bastón a los gobiernos franquistas.

Las nuevas bases ideológicas del nacional catolicismo se han infiltrado en las escuelas. El adoctrinamiento político afecta a la educación y la prensa. La Religión y la Formación del Espíritu Nacional se convierten en asignaturas obligatorias en todos los niveles de la enseñanza. Se suprime la libertad de cátedra y la coeducación. La Iglesia queda encargada de inspeccionar y controlar todo el sistema educativo: el Opus Dei, y grupos afines, en los niveles medios y altos, la Falange, en enseñanza Primaria, a cuyo frente estaban maestros sin título, excombatientes o monjas.

En todas las Escuelas del Magisterio debía aparecer colgado un crucifijo, una imagen de la virgen y otra del Jefe del Estado. Las maestras y maestros estaban obligados a asistir a campamentos y albergues organizados por el Frente de Juventudes o la Sección Femenina. Se implanta la Formación politico social en tres cursos.

Hacia 1950 tiene lugar en la sociedad española el inicio de una lenta evolución hacia el modelo de sociedad europea occidental. En 
1953, los acuerdos con los E.E.U.U. producen un primer pequeño desarrollo que va a favorecer el inicio minoritario del turismo y las primeras salidas de emigrantes hacia Europa. Ese pequeño desarrollo da lugar tanto a una pequeña expansión del movimiento obrero, como, sobre todo, al inicio de la formación de nuevas clases medias que aspiraban a nuevas formas de vida consumistas y a una mayor secularización de valores para utilizar los modelos de desarrollo en plena expansión neocapitalista de la sociedad europea en reconstrucción tras la II Guerra Mundial. A consecuencia de todo ello, tiene lugar la primera gran crisis política del régimen. Este conflicto resulta un momento determinante para el renacimiento del movimiento obrero clandestino que tiene lugar, fundamentalmente, a través de las protestas universitarias de la generación del 56 (ORTÍ, 2001) y el choque final de febrero de aquel año; que provocó la destitución de Joaquín Ruíz-Jiménez como Ministro de Educación Nacional y supuso el reencuentro de la minoría intelectual crítica. El viejo sistema de enseñanza se va a sustituir por otro que responda a las necesidades de modernización que comienzan a aparecer en España - cambio que no modifica el sistema político.

En la década de los 60 comienza un período de recuperación económica ante la llegada del turismo, los acuerdos con los Estados Unidos y la repatriación de los ahorros de los emigrantes en Europa. La situación afecta a la educación. En estos años aparecen los tecnócratas: administrativos del estado, generalmente del Opus Dei, en principio, expertos para resolver técnicamente los problemas del sistema educativo.

A partir de entonces, se produce un incremento de la sociedad de bienestar. Las familias rurales se desplazan hacia las capitales para trabajar en fábricas o empresas buscando mejor suerte para su descendencia. La sociedad de consumo comienza a intensificarse. La densidad demográfica en los cinturones de las grandes ciudades requiere escolarizar a la población infantil. Maestras y maestros, que vivieron de cerca esta explosión demográfica, tuvieron que enfrentarse a la nueva situación.

El régimen no ha cambiado, las costumbres sí. España se aleja del franquismo de los años cuarenta y el obsoleto sistema educativo será pronto sustituido para responder a las nuevas demandas sociales que introduce la industrialización y modernización que tienen lugar con el resurgir de la economía y la exigencia de mano de obra entre 1962 y 1968.

Por Orden Ministerial de 1 de junio de 1967 se modifica la organización y el régimen de las Escuelas de Magisterio. El nuevo Plan del 67, que se presentó con carácter provisional y duraba 2 cursos, estaba inspirado en el Plan Profesional de la República, pues las didácticas eran más importantes que los contenidos. El camino hacia la transición española estaba dibujado. La mentalidad había cambiado hacía tiempo y las reformas no hacían más que tratar de dar respuesta a la descomposición de un régimen.

No obstante, se mantienen los presupuestos ideológicos del régimen, que se centran en la asignatura de Didáctica de la Formación del Espiritu Nacional, en la cual se realizan actividades diferentes para alumnas y alumnos. Sin embargo, se puede apreciar que el Plan trata de dar respuesta a los cambios que se han producido en la economía española, como muestra el programa de estudios. En la asignatura de Didáctica de la Geografía, aparecen puntos como Papel de la economía en el mundo actual.

La burocratización del sistema educativo arranca de la segunda Ley General de Educación - LGE (Ley 14/1970). Con la implantación de esta Ley se produce el paso del artesano al profesional de la educación. Los objetivos de la nueva Ley, que cambió la estructura del sistema anterior, dibujan el camino hacia los principios de igualdad que se van a instaurar con el tránsito hacia la democracia. Se entiende que la educación es un medio de movilidad y promoción social. Siguiendo la teoría funcionalista, se confía en la neutralidad de la escuela como medio de distribución igualitaria en el mercado de trabajo. 
Las necesidades de educación a finales de los 60 eran enormes. En los primeros años de la década de los setenta hubo una alta presencia de escuela privada: 60 ó 70 por ciento en todos los niveles exceptuando el Bachillerato. Se cierran las escuelas privadas minifundistas, al no reunir las condiciones mínimas que exige la administración. La oferta pública tiene una fuerte expansión de 1977 a 1982, que irá en aumento para casi todos los niveles de la enseñanza. Existía una alta demanda de Bachillerato de Secundaria, y era necesario reformar el conjunto del sistema educativo. La LGE unifica el tronco común de la enseñanza obligatoria, que fija hasta los 14 años. Esta Ley establecía una educación preescolar de carácter no obligatorio, ni gratuito; unificaba la Educación General Básica de 6 a 14 años y la dividía en ocho cursos y tres ciclos. Para acceder al bachillerato, que era de ciencias o de letras, se pedía el título de graduado escolar. La Ley integra por primera vez una Formación Profesional, que podía ser de primer nivel, sin exigir ningún requisito de acceso, y una Formación Profesional de segundo grado, en la que se obtenía el título de Técnico Especialista al final de tres años que duraban los estudios. A partir de entonces el sistema educativo se va a desarrollar a través de los niveles de Preescolar, Educación General Básica (EGB), Bachillerato y Educación Universitaria, y de la Formación Profesional y de la Educación Permanente de Adultos.

La Ley del 70, que reconoce la Educación como un servicio público del Estado, integra las Escuelas de Magisterio en la Universidad con el nombre de "Escuelas Universitarias de Formación del Profesorado de EGB.” El Estado está preocupado por el perfeccionamiento del profesorado, y ofrece unas soluciones para estimular a un cuerpo abatido y cansado de pasar penurias, que quizá sólo por vincular la profesión con el sacerdocio y el sacrificio ha sido capaz de soportar sus avatares, más llevaderos, por otro lado, por unas mujeres pacientes y acostumbradas a ocupar un lugar secundario en la sociedad.

El momento de inflexión clave más cercano de nuestro sistema educativo durante el siglo XX nos lleva a situarnos en la norma aprobada ya en democracia en 1990 - Ley Orgánica General del Sistema Educativo - LOGSE (Ley Orgánica 1/1990); momento en el que se incide de manera muy directa en la necesidad de modificar la metodología, paso imprescindible para modernizar la educación y avanzar por el camino de las libertades iniciado con el proceso de transición. El paso de la Ley General de Educación (LGE) a la Ley Orgánica General del Sistema Educativo (LOGSE) es el tránsito de un currículo cerrado a otro abierto; cambios hacia metodologías más lúdicas que activen el espíritu crítico; nuevos mecanismos de control: el proyecto curricular, el proyecto de centro, etc. Es el momento en que se agudiza el control y aumenta la burocratización del sistema educativo.

La LOGSE estableció la Formación Profesional Superior y estructuró el sistema y ordenación de las enseñanzas, ampliando la enseñanza obligatoria hasta los 16 años. La Ley Orgánica de la participación, evaluación y gobierno de los centros docentes en 1995, LOPEG (Ley Orgánica 9/1995), determinó las actividades extraescolares, la autonomía de gestión de los centros docentes, la inspección por las administraciones educativas y los órganos de gobierno de los centros docentes. En 2002, la Ley Orgánica de las Cualificaciones y de la Formación Profesional, adecua la Formación Profesional a las nuevas exigencias del sistema productivo y fomenta la formación y la readaptación profesional. Ese mismo año, 2002, la Ley Orgánica de Calidad de la Educación, LOCE (Ley Orgánica 10/2002), establece una Prueba General de Bachillerato, implanta diferentes itinerarios formativos en $3^{\circ}$ y $4^{\circ}$ de la Educación Secundaria Obligatoria (E.S.0), determina la gratuidad de la Educación Infantil (3-6 años), incorporando programas de Iniciación Profesional y modificando el sistema de elección de los Directores.

La LOGSE (1990) ha sido más una adaptación a las nuevas necesidades. La ley del 70 fue un cambio, no fue adaptar lo que hay, fue borrar lo que había y partir de nuevas ideas. 
La maquinaria de burocratización se acentúa nuevamente en 2006, año en que se aprueba la LOE (Ley Orgánica Educación 2/2006). Esta Ley deroga todas las anteriores menos la Ley Orgánica del Derecho a la Educación de 1985, LODE (Ley Orgánica 8/1985), que estableció el derecho a la educación, la participación de la sociedad en el sistema educativo y la financiación de centros públicos y privados, y cuyos puntos más polémicos fueron la financiación, la religión y el recorte de materias artísticas.

\section{Relación de los cambios culturales con las exigencias metodológicas en el XX}

No ha habido ni un solo cambio en política educativa que se haya visto acompañado de modificaciones en las formas de enseñar, en las metodologías. No son sólo, ni lo más importante, los contenidos los que varian en estas fases de cambio social que se han detallado en este artículo al compás de giros en políticas educativas - que no es lo mismo que te pidan opinión a que te den una orden; cómo llega a los discentes y cómo asumen los modelos culturales es clave. Desde mi punto de vista las metodologías lúdicas son mucho más efectivas que las memorísticas; las primeras se retienen, las segundas se olvidan tan rápido como se aprenden en muchas ocasiones.

La historia de las metodologías tiene mucho que ver con la del castigo. Sustituir las metodologías basadas en el castigo por metodologías participativas, fue un intento durante la Restauración del último cuarto del siglo XIX y una realidad durante la II República. Es decir, la historia de los castigos en la escuela y sus modalidades ha ido variando en función de las metodologías, éstas por los cambios en los sistemas políticos y éstos por la defensa de modelos religiosos o laicos según el modelo de poder político imperante. Así de fuerte y así de cierta es esta relación en el caso de nuestro país; aunque desde hace algún tiempo los castigos están prohibidos y penados. Hubo un tiempo en que el castigo estuvo permitido y se utilizaba se utilizaba el lema: La letra con sangre entra. La historia de los castigos en la escuela y sus modalidades ha dependido de tipos de metodología y modelos políticos. Ponerle a uno orejas de burro, de cara contra la pared o darle un bofetón no es algo que casará con los métodos pedagógicos de la Segunda República, momento clave en que los políticos liberales optaron por metodologías participativas y sin castigo para potenciar la comprensión y la participación.

Ha habido 40 años de dictadura. Periodo en que los cambios metodológicos incrementaron el ejercicio de la memoria y, en ocasiones la vuelta hacia el método lancasteriano para abaratar mano de obra ante la falta de personal en las escuelas públicas.

Durante el franquismo hubo maestras que utilizaban elementos del método lancasteriano como medida para paliar el déficit de profesorado que se produjo con la depuración del magisterio desde 1939. Una de ellas, Julia Ortés, maestra desde los 14 años, recuerda en su diario las medidas que tuvo que tomar. Defensora de la feminización y las cualidades de la mujer para realizar las funciones de maestra, optó por preparar a niñas de catorce años, con escasos conocimientos, pero más aventajadas, y convertidas en auxiliares de maestra.

Este criterio de selección garantizaba, por otro lado, conductas acordes con las demandas del régimen y el ideario religioso. Evidentemente, si es la maestra quien elige, dependiendo de sus preferencias ideológicas, en bastantes ocasiones los criterios religiosos y comportamientos impecables priorizan en esa elección por encima de los criterios científicos. De hecho, alguna de esta auxiliares eran elegidas aunque no supiera leer o escribir, ya aprendería después con ella (ORTÉS, 1998).

Pero durante esos años, ha habido profesionales de la educación cercanos a la ideología de la República y sus innovaciones metodológicas, que huyeron de las metodologías a las que los aldeanos estaban acostumbrados $\mathrm{y}$ fueron críticos con los métodos memorísticos 
instalados por el régimen franquista en las escuelas. Así recuerda la maestra anterior.

Yo moriré ya enseñando como enseñó mi padre, como enseñó mi abuelo. Todos estos modernismos que ahora tratan de traernos a la escuela, para ellos. La única modificación que se hizo en la escuela cuando ella llegó, cincuenta años antes, consistió en retirar el Crucifijo y las láminas de Historia Sagrada que adornaban las paredes, cundo el Gobierno de la Segunda República decretó la enseñanza laica. La vieja Obaya lo recogió todo amorosamente, y después escupió sobre la bandera republicana. (MEDIO, 1993, p. 95)

En el caso de esta maestra republicana, las orientaciones pedagógicas americanas de la New School (modelos de educación que defienden una enseñanza individualizada para fomentar la creatividad y responsabilidad del alumno); o el sistema Dalton (enseñanza secundaria basada en el aprendizaje individual y en la autonomía del alumno para fomentar el trabajo de grupo), con que entra en contacto en sus años de estudiante, son sus referencias de renovación metodológica. Por ello, aguantando las críticas provocadas por el ambiente de hostilidad hacia los modernismos de las metodologías participativas, opta por ellas para motivar a los estudiantes con su propio trabajo. Evidentemente tropezará con la dura realidad: modelos contraculturales en unas aldeas rurales donde estaban acostumbrados a ese lema que reza: la letra con sangre entra.

No se va a jugar a la escuela, sino aprender, que no somos ricos, que hay que empezar enseguida a ganarse la vida [...]. Antes se enseñaba bien al que quería aprender... Qué regletazos daba la vieja... Pero como aprender... uno aprendía..., ahora parece que se enseña de otra manera. (MEDIO, 1993, p. 95, 149)

Las normas utilizadas por la maestra anterior habian producido un modelo de valores en el alumnado acordes con los métodos memorísticos tradicionales; todo ello en un escenario desolador, con un armario que guarda celosamente banderas de España cosidas y bordadas por la propia maestra (las Labores, que hasta 1968 no desaparece del currículo de las escuelas de magisterio femeninas, era motivo de orgullo y signo de distinción de clase social), mapas, no están pensados para producir los valores que ella quiere inculcar: tolerancia, respeto e igualdad. Los viejos y los nuevos métodos, reflejo de modelos políticos e ideológicos, entran en conflicto, pues su entusiasmo renovador chocará con las paredes de una escuela que refleja la historia de España.

Pero las políticas educativas iban a producir una fuerte modificación de las metodologías. Eso fue lo que sucedió en España en la década de los 80, momento en que el Partido Socilisita Obrero Español (PSOE) ganó las elecciones. La línea recta hacia el progreso siguió su curso: intereses y valores culturales de las clases sociales excluidas hasta entonces del poder, la política y la educación se fueron incorporando al tejido social con la llegada al poder de representantes políticos de la clase obrera, produciendo un lento cambio de mentalidad y de metodologías. Los efectos de este cambio social y político se plasmaron en los sistemas educativos, que fueron reformados al regular la Ley Orgánica General del Sistema de Enseñanza (LOGSE) en la década de los 90. ¿Qué cambia en la escuela? Priorizan los valores, modifican las metodologías, hacen obligatoria la educación hasta los 16 años y permiten el paso de un curso a otro con asignaturas suspensas. ¿Por qué? El objetivo era conseguir la igualdad de oportunidades e incorporar los valores de la clase obrera a los sistemas educativos. De esta manera, la cultura de la diferencia, creía el legislador, iría sustituyendo a la cultura estatutaria de los 70 a través del propio sistema educativo para conseguir un progreso social centrado en la igualdad de oportunidades de clase y de género. La igualdad étnica fue un proceso más tardío, 
pues hasta mediados de los 90, momento de auge económico, a España no llegan inmigrantes de otros países. Este nuevo fenómeno da lugar a otro cambio social significativo e imprevisto para los sistemas educativos. Así, con el paso de los 80 a los 90, la cultura de la diferencia fue cediendo el paso a la cultura de la diversidad. Cambió la estructura social y cambió la forma de pensar de las y los españoles.

Las exigencias metodológicas, que van en aumento con las siguientes políticas educativas con la promulgación de la Ley Orgánica General del Sistema Educativo de 2006, nos llevan hasta el sinsentido actual: exigir más innovaciones metodológicas masificando las aulas es como hipotecar la cultura. No se puede obtener lo mismo, o más, cuando no hay inversión, innovación o investigación en educación. No sólo se reduce el sueldo o la plantilla de profesorado, se reduce la calidad y se desespera a todo profesional que se siente frustrado al no poder obtener los resultados deseados. Hipotecar la cultura es el mayor fallo de un político. Si de hacer cuentas se trata hay que ser consecuentes con el dinero que uno tiene para amueblar una vivienda. Es decir: el edificio de la educación cambia su mobiliario cuando cambia de propietario, de poder político, pero a nadie con unos mínimos de sensatez se le ocurre amueblar con contenidos y metodologías costosos cuando ese presupuesto no llega. No se puede vender calidad donde ésta no se puede producir, y el destino de la educación en España, desafortunadamente, va por ese camino.

Quisiera terminar recordando el testimonio de una maestra nacida en 1904. Ella, como otras y otros, usaba la palmeta, que recibía el nombre de "doña milagros"; parece que una vez que se utilizaba "se conseguian milagros". Relataba en la entrevista un recuerdo imborrable en su memoria: era el caso de un maestro del pueblo que consiguió que todos sus alumnos aprendieran a leer. “¿Qué método utilizaba”?, pregunté. Con los ojos abiertos, hablando en presente, la maestra relata una imagen tétrica más apta para una película de miedo que para ser contada como una realidad vivida dentro de una escuela, y menos aún, permitida por las autoridades y el propio sistema educativo. Parece que el buen señor, un maestro, agarraba del cuello a los alumnos y les obligaba a dirigirse hacia un pozo que había en el patio. Llegado el momento, le cogía de los pies y amenazaba con soltarle si no cantaba la tabla de multiplicar o recitaba el vocabulario.

\section{Consideraciones finales}

He tratado de esbozar, desde la perspectiva de la sociología, un recorrido histórico del sistema educativo en España desde el comienzo de la escuela pública. Me he centrado en señalar que, más allá de las cuestiones económicas que implican recortes en educación, detrás de las políticas educativas ideadas se esconde un modelo ideológico interesado en dotar a la población de un nivel cultural mayor o menor, asentando así valores acordes con las conductas ideadas: pasivas, críticas, participativas, etc.

Esto ha sido lo que ha sucedido en España. Es decir, metodología y currículos han sido elegidos con distintas finalidades sociales y económicas por los representantes políticos. Ese proceso se ha pasado en otros países como es el caso de Brasil (FERRETTI, 2008; VIANNA, 2011). Así, desde el advenimiento de la democracia parlamentaria, los dos partidos mayoritarios: Partido Socialista Obrero Español (1983-1996, con Felipe González como presidente; 2004-2011, con José Luis Rodríguez Zapatero) y Partido Popular (1996-2004, con José María Aznar y desde 2011 con Mariano Rajoy), han optado por implantar leyes de educación acordes con sus ideologías.

La Ley de Ordenación General del Sistema Educativo, una ley clave para comprender las iniciativas contra la política neoliberal, se ha llenado de contenido social hasta convertirse en centro de debate social y político. De hecho, esta Ley es un referente histórico que señala un cambio de equilibrio en los poderes políticos. Se trata de un momento de esfuerzo por incorporar, a través de la escuela pública, 
el modelo de cultura de la clase obrera desde la escuela para hacer efectivo el Principio de Igualdad de Oportunidades.

Hay llaves que van abriendo puertas y dan paso a un nuevo periodo histórico. Sin esas llaves, que nos permiten ver las relaciones entre cultura, metodología y política educativa, no es posible visualizar cambios de rumbo en la escuela pública de España. Por ello, he ido incidiendo en fechas significativas, montañas para visualizar campos que se abren a un nuevo proceso histórico que afecta directamente al modo de entender la educación.

En mi opinión, no es posible comprender lo que está pasando en este país desde el comienzo de la gran crisis económica del siglo XXI, una vuelta de tuercas sin precedentes desde el asentamiento de la democracia, sin buscar los genes del sistema educativo y comprender su evolución. Es decir, en España no ha habido ni un solo momento en la historia de la escuela pública en el cual los políticos, y en muchas ocasiones la propia Iglesia, no hayan sido los encargados de diseñar los contenidos, currículos y metodologías que dan forma a las políticas educativas.

El problema actual no es sólo económico. Se trata también de una forma de diseñar el futuro de la escuela pública desde modelos ideológicos. Este ha sido el objetivo de este artículo: rastrear en la historia para comprender la evolución de los modelos culturales y su relación con las políticas educativas. Que la y el lector entiendan esa relación ha sido mi objetivo. 


\section{Referencias}

CARABAÑA, Julio. Bolonia: rectificar a tiempo. El País. Madrid, España, 25 mai., 2009. Sociedad, Actualidad. Disponible en: <http://sociedad.elpais.com/sociedad/2009/05/25/actualidad/1243202402_850215.html>.

CORTINA, Adela. Educar para la ciudadanía justa. El País. Madrid, España, 20 jun., 2006. Tribuna. Disponible en: <http://elpais. com/diario/2006/06/20/opinion/1150754414_850215.html>.

DECRETOS DEL REY FERNANDO VII, I. Madrid: Imprenta Real, 1816.

X. Madrid: Imprenta Real, 1826.

ELIAS, Norbert. El proceso de civilización. Investigación sociogenética y psicogenética, Madrid: Fondo de Cultura Económica, 1979.

ESPAÑA. Ley 14/1970 General de Educación y Financiamiento de la Reforma Educativa (LGE), de 4 de agosto de 1970. Boletín Oficial del Estado (BOE), n. 187, p. 12525-12546.

ESPAÑA. Ley Orgánica 8/1985 reguladora del Derecho a la Educación, de 3 de julio de 1985. Boletín Oficial del Estado (BOE), n. 159, p. 21015-21022, 4 de julio de 1985.

ESPAÑA. Ley Orgánica 1/1990 de Ordenación General del Sistema Educativo (LOGSE), de 3 de octubre de 1990. Boletín Oficial del Estado (BOE), n. 238, p. 28927-28942, Jueves 4 octubre 1990.

ESPAÑA. Ley Orgánica 9/1995 de la Participación, la Evaluación y el Gobierno de los centros docentes, de 20 de noviembre de 1995. Boletín Oficial del Estado (BOE), n. 278, p. 3351-33665.

ESPAÑA. Ley orgánica 10/2002 de calidad de la educación, de 23 de diciembre de 2002. Boletín Oficial del Estado (BOE), n. 307, p. $45188-45220$.

ESPAÑA. Ley Orgánica Educación 2/2006 (LOE), 4 de mayo de 2006. Boletín Oficial del Estado (BOE), n. 106, p. 17158-17207, jueves, de 3 de mayo, 2006.

ESPAÑA. Ley Orgánica 5/2002, de 19 de junio, de las Cualificaciones y de la Formación Profesional. Boletín Oficial del Estado (BOE), n. 143, p. 22437- 22442.

FERRETTI, Celso. A reforma do ensino técnico da década de 1990 e a prática de professores na sua implementação. In: MONFREDINI, Ivanise (Org.). Políticas educacionais, trabalho e profissão docente. São Paulo: Xamã, 2008. v. 1, p. 101-114.

GIBERT, Francisco Xavier. La esperanza feliz de España cumplida en la venida del Señor Rey D. Fernando VII. Cantata a cuatro voces, Madrid: Imprenta de Burgos, 1815.

GIMENO SACRISTÁN, José et al. (Orgs). El sistema educativo: una mirada crítica. Barcelona: Cisspraxis, Sociedad Anónima, 2004. HARGREAVES, Andy. Changing teachers, changing times: Teachers' work and culture in the postmodern age. London: Cassell, 1994. HOPMANN, Stefan. El movimiento de enseñanza mutua y el desarrollo de la administración curricular: un enfoque comparado. Revista de Educación, n. 295, p. 291-316, 1991.

MARTínEZ ALCUBILLA, Manuel. Códigos antiguos de España. Madrid, 1880.

MEDIO, Dolores. Diario de una maestra. Madrid: Castalia, 1993.

MELCÓN BELTRÁN, Julia. La formación del profesorado en España: 1837-1914. Madrid: M.E.C., 1992.

MONTESINO, Pablo. Manual para los maestros de escuelas de párvulos. Bilbao: Imprenta Nacional, 1840.

MOYANO SAMANIEGO, Claudio. Ley de Instrucción pública, S.M, 9 de septiembre de 1857. Madrid: Imprenta Nacional, 1857. 
ORTÉS, Julia. Vivencias de una maestra. Madrid: Narcea, 1998.

ORTÍ, Alfonso. En el margen del centro: la formación de la perspectiva sociológica crítica de la generación de 1956. Revista Española de Sociología, n. 1, p.119-163, 2001.

PÉREZ GALÁN, Mariano. La enseñanza en la Segunda República. Madrid: Mondadori, 1988.

REVISTA CONSIGNA, n. 10, Diciembre,1941.

RUIZ BERRIO, Julio. Política escolar de España en el siglo XIX (1808-1833). Madrid: C.S.I.C., 1970.

SAN ROMÁN, Sonsoles. Las primeras maestras. Los orígenes del proceso de feminización docente en España. Barcelona: Ariel, 2011 ( $4^{\mathrm{a}}$ ed.).

(Org). La participación de las maestras en el actual proceso educativo: marcos institucionales y contextos motivacionales. Madrid, Ministerio de Asuntos Sociales (1+D+I), Boletín Oficial del Estado, n. 20, 2007- 2009.

SANZ DÍAZ, Federico. El proceso de institucionalización e implantación de la Primera Enseñanza en España, 1838-1870. Cuadernos de investigación histórica, n. 4, p. 229-267, 1980.

SCANLON, Geraldine. La mujer y la instrucción pública: de la Ley Moyano a la segunda República. Historia de la Educación, n. 6 , p. 34-50, 1987.

TAMAMES, Ramón. La República: la era de Franco. Madrid: Alianza Universidad, 1973.

VIANNA, Cláudia. Gênero, sexualidade e políticas públicas de educação: um diálogo com a produção acadêmica. Pro-Posições, Campinas, v. 23, n. 2 (68), p. 127-143, maio/ago. 2012.

VIÑAO FRAGO, Antonio. Sistemas educativos, culturas escolares y reformas. Madrid: Morata, 2002.

Escuela para todos. Educación y modernidad en la España del Siglo XX. Madrid: Ed. Marcial Pons, 2004.

WEBER, Max. La ética protestante y el espíritu del capitalismo. Barcelona: Editorial Península, 1985.

Recebido en: 29.06.2012

Aprobado en: 08.10.2012

Sonsoles San Román Gago es Catedrática de la Escuela Universitaria del Departamento de Sociología de la Facultad de Ciencias Económicas y Empresariales de la Universidad Autónoma de Madrid, España. 